\title{
The integrated biomarker response revisited: optimization to avoid misuse
}

\author{
S. Devin ${ }^{a, 1, *}$, T. Burgeot ${ }^{b}$, L. Giambérini ${ }^{a}$, L. Minguez $^{a}$, S. Pain-Devin ${ }^{a}$
}

\begin{abstract}
a CNRS UMR 7360, Laboratoire Interdisciplinaire des Environnements Continentaux (LIEC), Université de Lorraine, Metz, 57070, France

b IFREMER, Département Biogéochimie et Ecotoxicologie, Laboratoire d'Ecotoxicologie, IFREMER Centre de Nantes, Nantes, France

${ }^{1}$ Present address : LIEC, Campus Bridoux, Rue du Général Delestraint, Metz, 57070, France
\end{abstract}

*: Corresponding author : Simon Devin, tel : +33 387378402 ; email address : simon.devin@univ-lorraine.fr

\begin{abstract}
:
The growing need to evaluate the quality of aquatic ecosystems led to the development of numerous monitoring tools. Among them, the development of biomarker-based procedures, that combine precocity and relevance, is recommended. However, multi-biomarker approaches are often hard to interpret, and produce results that are not easy to integrate in the environmental policies framework. Integrative index have been developed, and one of the most used is the integrated biomarker response (IBR). However, an analysis of available literature demonstrated that the IBR suffers from a frequent misuse and a bias in its calculation. Then, we propose here a new calculation method based on both a more simple formula and a permutation procedure. Together, these improvements should rightly avoid the misuse and bias that were recorded. Additionally, a case study illustrates how the new procedure enabled to perform a reliable classification of site along a pollution gradient based on biomarker responses used in the IBR calculations.
\end{abstract}

Keywords: Biomarkers ; Integrated Index ; Environmental risk assessment ; Pollution ; Water Framework Directive 


\section{Introduction}

Aquatic ecosystems, being the final receptacle of pollutants, suffer from high levels of perturbation (Vörösmarty et al., 2010). To face this issue, international policies (Water Framework Directive, WFD, and Marine Strategy Framework Directive, MSFD, in Europe) have emerged with the aim to evaluate, protect and restore freshwater and marine ecosystems. These policies rely on several strategies of ecosystem health evaluation, essentially based on chemical concentrations and on biological communities structure and composition. However, some claim for an additional intermediate approach focusing on biomarker responses at the individual level have emerged recently for the future MSFD application (Schlenk, 1999; Galloway et al., 2006; Hagger et al., 2008; Lam, 2009; Sanchez and Porcher, 2009; Lyons et al., 2010; Artigas et al., 2012).

The multibiomarker approach is already widely used for in situ assessment of ecotoxicological effects of contaminants and for understanding the relationships (1) between biomarkers and (2) between biomarkers and contamination levels of studied sites. However, to transfer these procedures from scientists to environmental managers, integrative tools need to be proposed. By now, some indexes exist to synthetize the responses of biomarkers in a single and simple measure (Beliaeff and Burgeot, 2002; Chèvre et al., 2003; Aarab et al., 2004; Broeg et al., 2005; Dagnino et al., 2007; Yeom and Adams, 2007; Izagirre and Marigómez, 2009). Among them, one of the most popular is the Integrated Biomarker Response (IBR) proposed by Beliaeff and Burgeot (2002).

The Integrated Biomarker Response (IBR) is a method that provides both a graphical synthesis of the different biomarker responses and a numeric value that integrates all these responses at once. The IBR is the sum of the area defined by the k biomarkers arranged in a radar diagram (fig.1), following a prior step of biomarker responses standardization. All the calculation procedure and data representation could be performed with classical spreadsheet programs. However, in their initial publication, the authors provided two calculation methods: the first one is a complicated formula (fig. 1) that works wathever the number of biomarker is, while the second one is a simplified formula that works only when 4 biomarkers are used (Beliaeff and Burgeot 2002).

The attractiveness for simplicity led to frequent misuse of the IBR. On the 75 publications citing the original publication (citations of the article of Beliaeff and Burgeot (2002) were collected with ISI web of knowledge - Thomson Reuters-), 31 only cite the IBR with no application, and 44 were applications with a multibiomarker approach. We finally evidenced a misuse of the simplified formula in more than $50 \%$ of them, with 23 publications with formula errors, 15 with a good use and 6 where the calculation method was not described. This misuse led to an increase of the IBR value with the number of biomarkers considered, that Broeg and Lehtonen tried to correct by dividing the IBR value by the number of biomarkers studied (Broeg and Lehtonen, 2006).

Moreover, the final outcome of the calculation process highly depends on the sequential organisation of the biomarkers (Beliaeff and Burgeot, 2002; Kammann et al., 2005; Leinio and Lehtonen, 2005; Broeg and Lehtonen, 2006). Considering that this index is classicaly used to realize a site classification according to a pollution gradient, the identified misuse can lead to important consequences regarding ecosystem health evaluation. Indeed, a change of the sequential organisation of biomarkers in the diagram can change the IBR value and so completely modify the score of a site that can move from a "more polluted" status to a "less polluted" one or inversely. This will be illustrated in the case study presented further.

In order to limit the effect of biomarker arrangement, two suggestions were made by Beliaeff and Burgeot (2002). They proposed to arrange biomarkers according to (i) similarities in their biological function or (ii) their ability to discriminate sites with different levels of contamination. The main objection to the first proposition is that, in many biomarker batteries, authors looked for responses that represents a wide range of biological functions that are, if possible, not correlated to each other. For their second proposition, the ability to discriminate sites depends on the site contamination profiles: some biomarkers will be efficient to identify an organic contamination, others will be better for a metallic contamination, thus in a multi-sites surveys, it will not be always 
the same biomarkers that will be the most efficient to discriminate two given sites (and that's precisely why we use batteries).

In this context, we thus aim to propose a new procedure to resolve the main problems in the IBR application that are formula misuse and arbitrary choice of biomarker arrangement.

\section{Calculation}

\subsection{Formula simplification}

The IBR calculation is based on 4 major steps, described in Beliaeff and Burgeot (2002). The first three one are not modified, and we only simplified the formula on the fourth step.

(1) The mean value for a site $(X)$ was standardised using the mean value for all sites $(m)$ and the standard deviation for all sites (s) to produce a value we call $Y: Y=(X-m) / s$

(2) For each biomarker, we compute the value $Z=Y$ or $Z=-Y$ according to the expected biological effect, respectively activation or inhibtion.

(3) The value $S$ was computed, with $S=Z+\mid$ Min|, where Min is the minimal value observed for all sites for each biomarker.

(4) Finally, all the $S_{i}$ values were plotted on a radar diagram. The IBR is calculated as the total area diplayed by the radar diagram. Here, we go back to trigonometry basics to propose a new formula for the IBR, that is far more simple than the original one.

The area of the triangle defined by two successive biomarkers in a k-biomarker study where at least 4 biomarkers are considered is defined as (fig. 2):

$A_{i}=S_{i}^{*} S_{i+1}{ }^{*} \sin (2 \pi / k) / 2$.

And the IBR value is calculated as follow:

$$
\mathrm{IBR}=\sum_{\mathrm{i}=1}^{\mathrm{k}} \mathrm{Ai}
$$

This new formula can be applied only when 4 or more biomarkers are measured. However, this is not a limitation compared to the previous formula, since no study using the IBR was published with less than 4 biological responses measured.

\subsection{Calculation procedure}

The second weakness of the IBR is the biomarker sequence in the radar diagram, which is userdefined and does not always rely on conceptual basis. The risk is to produce by chance a particular structure of the diagram. Thus we wrote a procedure ${ }^{1}$ that creates all the possible circular permutations of $k$ biomarkers. It results on a $(k-1)$ ! matrix of IBR values that allows to calculate the median IBR for a site and to prioritize IBR values among sites in a more confident

\footnotetext{
${ }^{1}$ The $\mathrm{R}$ code to calculate all possible values of the IBR and to produce the associated graphics is available on demand to the corresponding author.
} 
way. It results on a matrix of 6 values for 4 biomarkers, 24 values for 5 biomarkers, 120 values for 6 biomarkers and so on.

Those values can be used to perform statistical analysis and to look for between-site differences. As it will be illustrated by the case study presented thereafter, we recommend non parametric tests, because the permutation procedure does not always lead to a normal distribution of the IBR values within a site.

\section{Case study}

A case study using this method is presented, based on the results of a survey of 8 sites (fig. 3) presenting contrasted levels of sediment contamination (fig. 4, table 1). A set of 8 biomarkers measured in the bivalve Dreissena polymorpha, not correlated to each other, is used. The nature and the response of these biomarkers is not the topic of this study, thus we will develop neither their interest nor their measurement method. Natural populations of zebra mussels were sampled in spring, in a short time-frame to avoid a bias link to strong variations of their physiological status. We focused on antipollution defences which are early warning systems involved in (1) protection of organisms against the entry of contaminants, (2) their sequestration, (3) their inactivation (metabolism) and (4) their elimination. The following endpoints were studied: multixenobiotic defence MXR (transport assay), pi glutathion-S-transferases in the gills and in the digestive gland (gene expression), lysosomal defence (histochemical determination), anti-oxidant defence (Selenium-dependent Glutathion Peroxidase gene expression) and metallothioneins (polarographic determination in digestive gland and gene expression in gills). Malondiadlehyde (MDA) was also assessed in order to provide information about toxic effects in collected organisms.

The permutation performed for this set of biomarkers resulted in a matrix of 5040 IBR values. First, this case study enabled to point out that the distribution of the compiled values is not always normal (fig. 5). We thus recommend to describe the information provided by the permutation procedure by indicators that are meaningfull for non normal data distribution, i.e. by using the median and the quartile rather than the mean and the standard deviation. Similarly, between-site comparisons should rely on non-parametric method. The hypothesis tested by non-parametric tests like the Kruskal-Wallis one is not a simple comparison of the main tendency of several samples, but the overall comparison of value distribution. It means that the outcome of a nonparametric test performed on the computed IBR values provides information about the similarity of IBR distribution between sites. Thus, when IBR distribution are not similar, it can be concluded that sites present different patterns of stress.

Our results also highlight the importance of the arrangement in the representation of ecotoxicological effects in each site (fig. 6). When the 5040 values are compiled, it evidenced the variability of the IBR values, that is our main concern. Indeed, the direct consequence of this variability is a different prioritization of contaminant effects depending on the biomarker sequence (table 2), that could lead to misunderstanding of contamination consequences on biota if only one arangement is considered. Table 2 shows that both the value and the rank of the IBR index for a site exhibit high variations (e.g. the site labelled $\mathrm{E}$, that could be either the less or the most contaminated one depending on the permutation chosen), and that a more significant IBR value is obtained through the median calculated across all the possible arrangement.

If we try to compare the old version of the IBR calculation and the new one proposed here, it is necessary to remind that the value calculated by the original procedure is just one of the 5040 values computed, that could be either far or near of the "true" value estimated by the median of all the possible values. For example, fig. $6 \mathrm{c}$ presents two possible site classification according to two particular arrangements of the biomarkers on the radar diagram. The old version of the IBR calculation would have given us only the results of either the classification 273 or 4928 , without considering these two possibilities. 
Finally, our case study evidenced that the IBR is a pertinent index to evaluate site contamination, with a correlation between PAHs contamination levels in sediment and the median IBR value $\left(r_{\text {pearson }}=0.721, p=0.04\right)$. No correlation with PCBs and metals levels were found. However, the contamination levels considered here only reflect site quality, but no assessment of contaminant biodisponibility, nor accumulation in mussel tissues were performed to better describe exposure of each population. Our approach is global and needs to be refined through the application of other batteries of biomarkers and also by including model organisms at other trophic levels.

\section{Conclusions}

The results of the case study evidenced the influence of the biomarker order on the diagram and the need to adopt neutral procedure that is not user-defined. Indeed, the consequence of this biomarker sequence is a different prioritization of contaminant effects, that could lead to misunderstanding of contamination consequences on biota. In their study, Raftopoulou and Dimitriadis (2010) criticized the IBR that was not able to classify correctly sites on a pollution gradient. However, as we illustrated in the previous case study, it could have been linked to the specific biomarker arrangement on the radar diagram. The proposed procedure thus needs to be confronted to numerous other case studies, involving other stressors and other species to confirm its ability to reflect pollution gradient and population health in variable contamination contexts.

Finally, the new calculation procedure avoids the order bias, and makes this tool statistically more powerful and biologically more suitable. Considering the need of multibiomarker approaches to understand (1) the complexity and the variability of biological responses and (2) the relationships between population health and site contamination, our study provides an efficient and optimized tool to integrate these data and avoid subjectivity in the final outcome of the method.

\section{Perspectives}

Some points still need to be improved to use this index for biomonitoring: (1) the IBR is a useful value for site comparison, but not an absolute index of biological stress levels, because biomarker responses are standardised based on the studied sites and (2) the user should define a priori whether the biomarker response to contamination is an induction or an inhibition. To eliminate this drawback, we should be able to define reference values for each biomarker used in the IBR to express the value as a percentage of variation from this reference value. Thereby, an absolute scale of IBR variation could be established, and each IBR calulation would be independentant of the set of site considered. Thus, studies focusing on the natural variations of biomarkers and aiming to understand, besides contaminants, the environmental variables and physiological status that influence biomarker values have to be developped (Munkittrick et al., 2009; Xuereb et al., 2009; Coulaud et al., 2011).

\section{References}

Aarab, N., Champeau, O., Mora, P., Daubeze, M., Garrigues, P., Narbonne, J.F., 2004. Scoring approach based on fish biomarkers applied to French river monitoring. Biomarkers 9, 258-270.

Artigas, J., Arts, G., Babut, M., Caracciolo, A.B., Charles, S., Chaumot, A., Combourieu, B., Dahllöf, I., Despréaux, D., Ferrari, B., Friberg, N., Garric, J., Geffard, O., Gourlay-Francé, C., Hein, M., Hjorth, M., Krauss, M., De Lange, H.J., Lahr, J., Lehtonen, K.K., Lettieri, T., Liess, M., Lofts, S., Mayer, P., Morin, S., Paschke, A., Svendsen, C., Usseglio-Polatera, P., van den Brink, N., Vindimian, E., Williams, R., 2012. Towards a renewed research agenda in ecotoxicology. Environmental Pollution 160, 201-206. 
Beliaeff, B., Burgeot, T., 2002. Integrated Biomarker Response : A useful tool for ecological risk assessment. Environmental Toxicology and Chemistry 21, 1316.

Broeg, K., Lehtonen, K.K., 2006. Indices for the assessment of environmental pollution of the Baltic Sea coasts: Integrated assessment of a multi-biomarker approach. Marine Pollution Bulletin. 53, 508-522.

Broeg, K., Westernhagen, H. v., Zander, S., Körting, W., Koehler, A., 2005. The "bioeffect assessment index" (BAI): A concept for the quantification of effects of marine pollution by an integrated biomarker approach. Marine Pollution Bulletin 50, 495-503.

Chèvre, N., Gagné, F., Blaise, C., 2003. Development of a biomarker-based index for assessing the ecotoxic potential of aquatic sites. Biomarkers 8, 287-298.

Coulaud, R., Geffard, O., Xuereb, B., Lacaze, E., Quéau, H., Garric, J., Charles, S., Chaumot, A., 2011. In situ feeding assay with Gammarus fossarum (Crustacea): Modelling the influence of confounding factors to improve water quality biomonitoring. Water Research 45, 6417-6429.

Dagnino, A., Allen, J.I., Moore, M.N., Broeg, K., Canesi, L., Viarengo, A., 2007. Development of an expert system for the integration of biomarker responses in mussels into an animal health index. Biomarkers 12, 155-172.

Galloway, T.S., Brown, R.J., Browne, M.A., Dissanayake, A., Lowe, D., Depledge, M.H., Jones, M.B., 2006. The ECOMAN project: A novel approach to defining sustainable ecosystem function. Marine Pollution Bulletin 53, 186-194.

Hagger, J.A., Jones, M.B., Lowe, D., Leonard, D.R.P., Owen, R., Galloway, T.S., 2008. Application of biomarkers for improving risk assessments of chemicals under the Water Framework Directive: A case study. Marine Pollution Bulletin 56, 1111-1118.

Izagirre, U., Marigómez, I., 2009. Lysosomal enlargement and lysosomal membrane destabilisation in mussel digestive cells measured by an integrative index. Environmental Pollution 157, 1544 1553.

Kammann, U., Biselli, S., Reineke, N., Wosniok, W., Danischewski, D., Huhnerfuss, H., Kinder, A., Sierts-Herrmann, A., Theobald, N., Vahl, H.H., Vobach, M., Westendorf, J., Steinhart, H., 2005. Bioassay-directed fractionation of organic extracts of marine surface sediments from the North and Baltic Sea - Part II: Results of the biotest battery and development of a biotest index. Journal of Soils and Sediments 5, 225-232.

Lam, P.K.S., 2009. Use of biomarkers in environmental monitoring. Ocean and Coastal Management 52, 348-354.

Leinio, S., Lehtonen, K.K., 2005. Seasonal variability in biomarkers in the bivalves Mytilus edulis and Macoma balthica from the northern Baltic Sea. Comparative Biochemistry and Physiology CToxicology and Pharmacology 140, 408-421.

Lyons, B.P., Thain, J.E., Stentiford, G.D., Hylland, K., Davies, I.M., Vethaak, A.D., 2010. Using biological effects tools to define Good Environmental Status under the European Union Marine Strategy Framework Directive. Marine Pollution Bulletin 60, 1647-1651.

Munkittrick, K.R., Arens, C.J., Lowell, R.B., Kaminski, G.P., 2009. A Review of Potential Methods of Determining Critical Effect Size for Designing Environmental Monitoring Programs. Environmental Toxicology and Chemistry 28, 1361-1371.

Raftopoulou, E.K., Dimitriadis, V.K., 2010. Assessment of the health status of mussels Mytilus galloprovincialis along Thermaikos Gulf (Northern Greece): An integrative biomarker approach using ecosystem health indices. Ecotoxicology and Environmental Safety 73, 1580-1587. 
Sanchez, W., Porcher, J.-M., 2009. Fish biomarkers for environmental monitoring within the Water Framework Directive of the European Union. Trends in Analytical Chemistry 28, 150-158.

Schlenk, D., 1999. Necessity of Defining Biomarkers for Use in Ecological Risk Assessments. Marine Pollution Bulletin 39, 48-53.

Vörösmarty, C.J., Mclntyre, P.B., Gessner, M.O., Dudgeon, D., Prusevich, A., Green, P., Glidden, S., Bunn, S.E., Sullivan, C.A., Liermann, C.R., Davies, P.M., 2010. Global threats to human water security and river biodiversity. Nature $467,555-561$.

Xuereb, B., Chaumot, A., Mons, R., Garric, J., Geffard, O., 2009. Acetylcholinesterase activity in Gammarus fossarum (Crustacea Amphipoda): Intrinsic variability, reference levels, and a reliable tool for field surveys. Aquatic Toxicology 93, 225-233.

Yeom, D.-H., Adams, S.M., 2007. Assessing effects of stress across levels of biological organization using an aquatic ecosystem health index. Ecotoxicology and Environmental Safety 67, 286-295.

\section{Acknowledgement}

The authors thank the French INSU-EC2CO-Cytrix program for supporting this work, part of the Sydépop project. We would like to thank Carole Cossu-Leguille, François Rodius and Alain Geffard for their participation in the Sydépop project. 
Figure 1 : Calculation method of the IBR defined by Beliaeff and Burgeot (2002). Each axis of the star plot represents the standardized value $S_{i}$ of a biomarker $(B m k)$. Two successive biomarkers in the plot defines a triangle with an area $A_{i}$, and the IBR value is the sum of the $k$ areas. On the figure are presented the standard (a) and simplified (b) formulas.

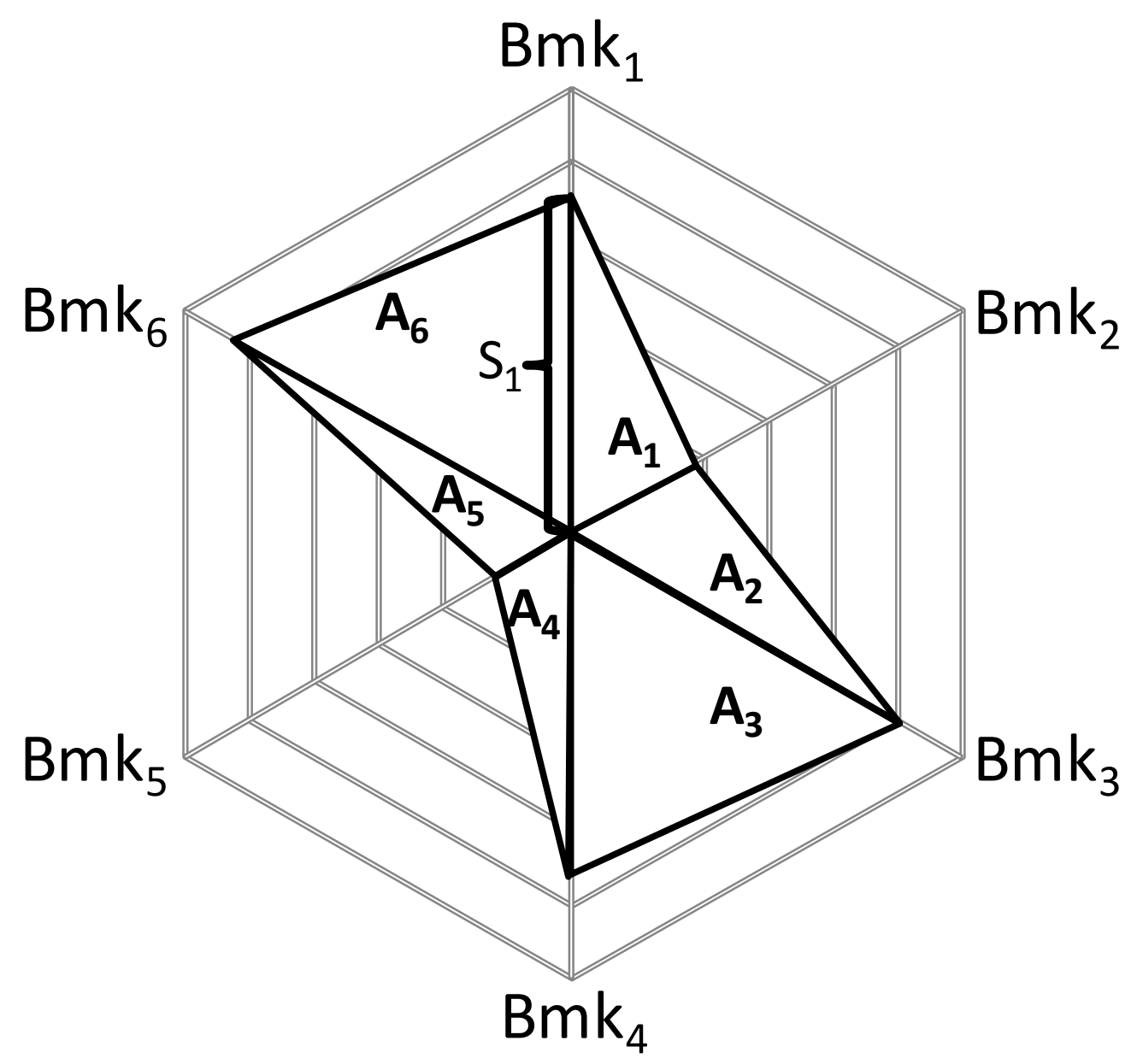

(a) Standard formula for $\mathrm{k}$ biomarkers:

$$
\begin{aligned}
& A \mathrm{i}=\frac{\mathrm{S}_{\mathrm{i}}}{2} \sin \beta\left(\mathrm{S}_{\mathrm{i}} \cos \beta+\mathrm{S}_{\mathrm{i}+1} \sin \beta\right) \operatorname{and} \beta=\operatorname{Arctan}\left(\frac{\mathrm{S}_{\mathrm{i}+1} \sin \alpha}{\mathrm{S}_{\mathrm{i}}-\mathrm{S}_{\mathrm{i}+1} \cos \alpha}\right) \\
& \mathrm{IBR}=\sum \mathrm{A}_{\mathrm{i}}
\end{aligned}
$$

(b) Simplified formula for 4 biomarkers:

$$
\operatorname{IBR}=\Sigma\left(\mathrm{S}_{\mathrm{i}}{ }^{*} \mathrm{~S}_{\mathrm{i}+1}\right) / 2
$$


Figure 2 :New calculation method for the triangle area. $\mathrm{h}$ is the height of the triangle formed by two successive biomarkers, and $\alpha$ is the angle formed by the two corresponding axes of the star plot.

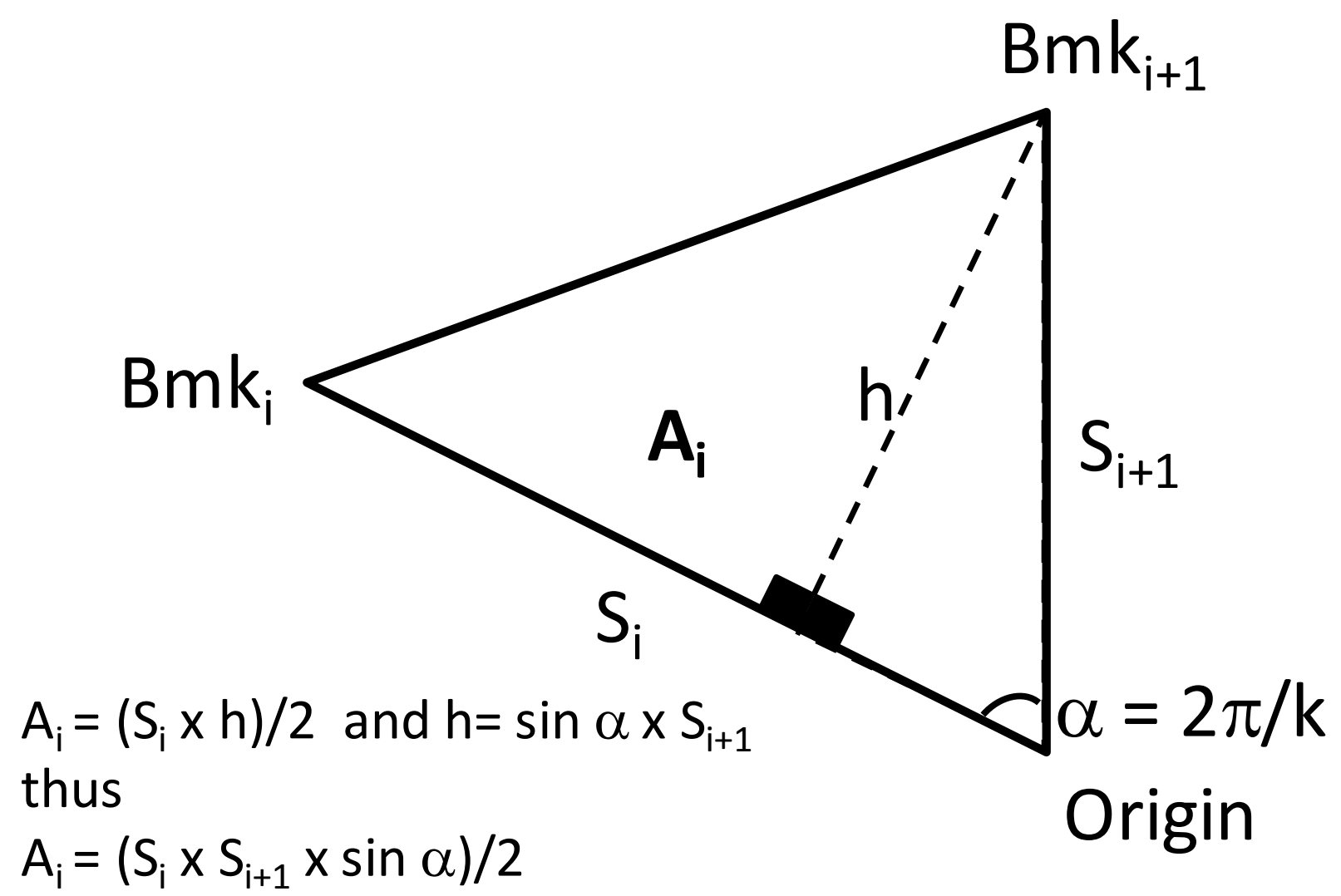


Figure 3 : Location of the 8 studied populations (France). Site and B are located on shipping channels connected to the Meuse River, C, D and E on the Moselle River, F and G on the Seine River and $\mathrm{H}$ on the Vilaine River.

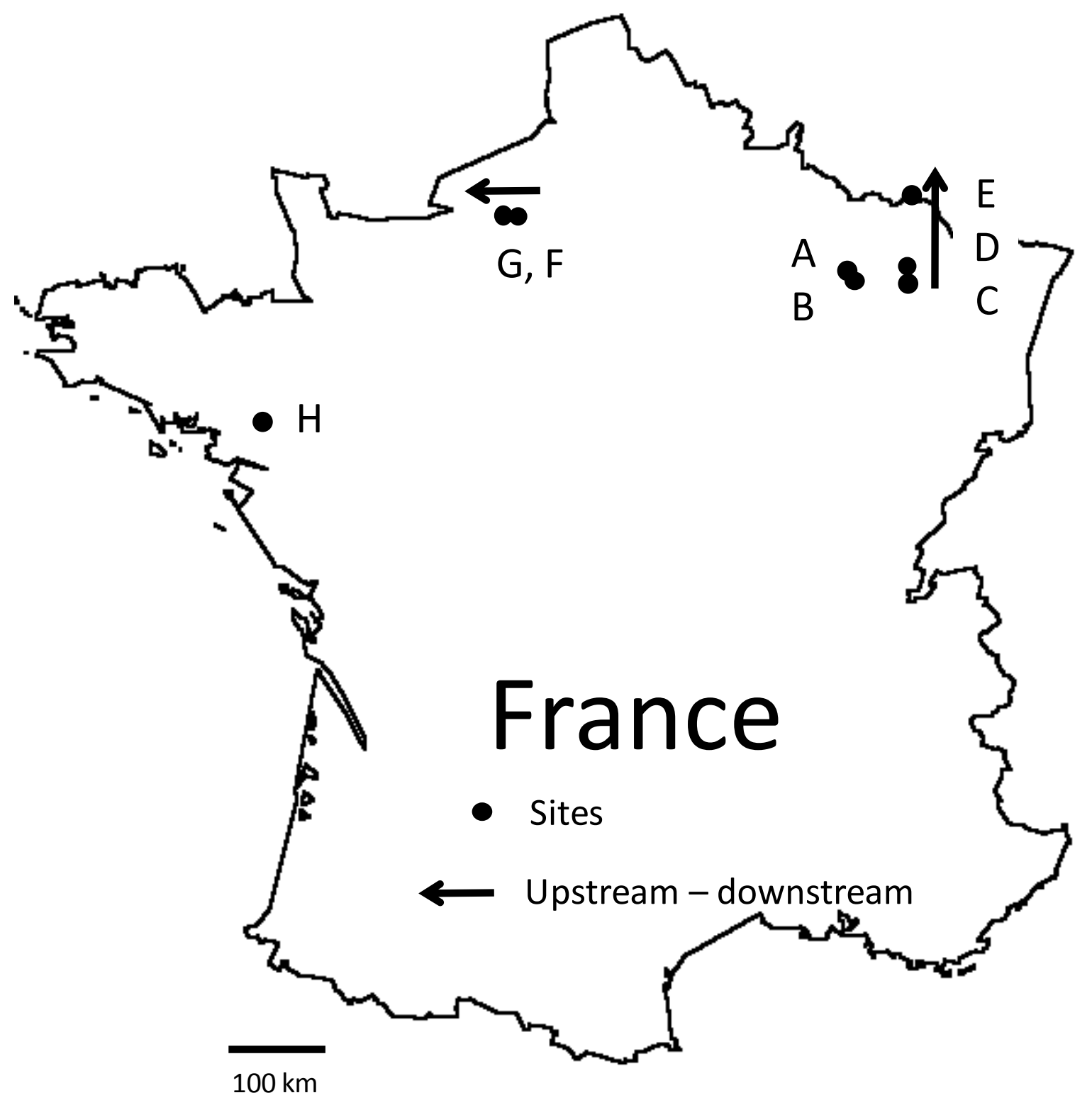


Figure 4 : Sediment contamination of the 8 studied sites. Contamination is calculated as the mean rank of a site among all sites for all the pollutants of a family (ie PAHs, PCBs and metals).

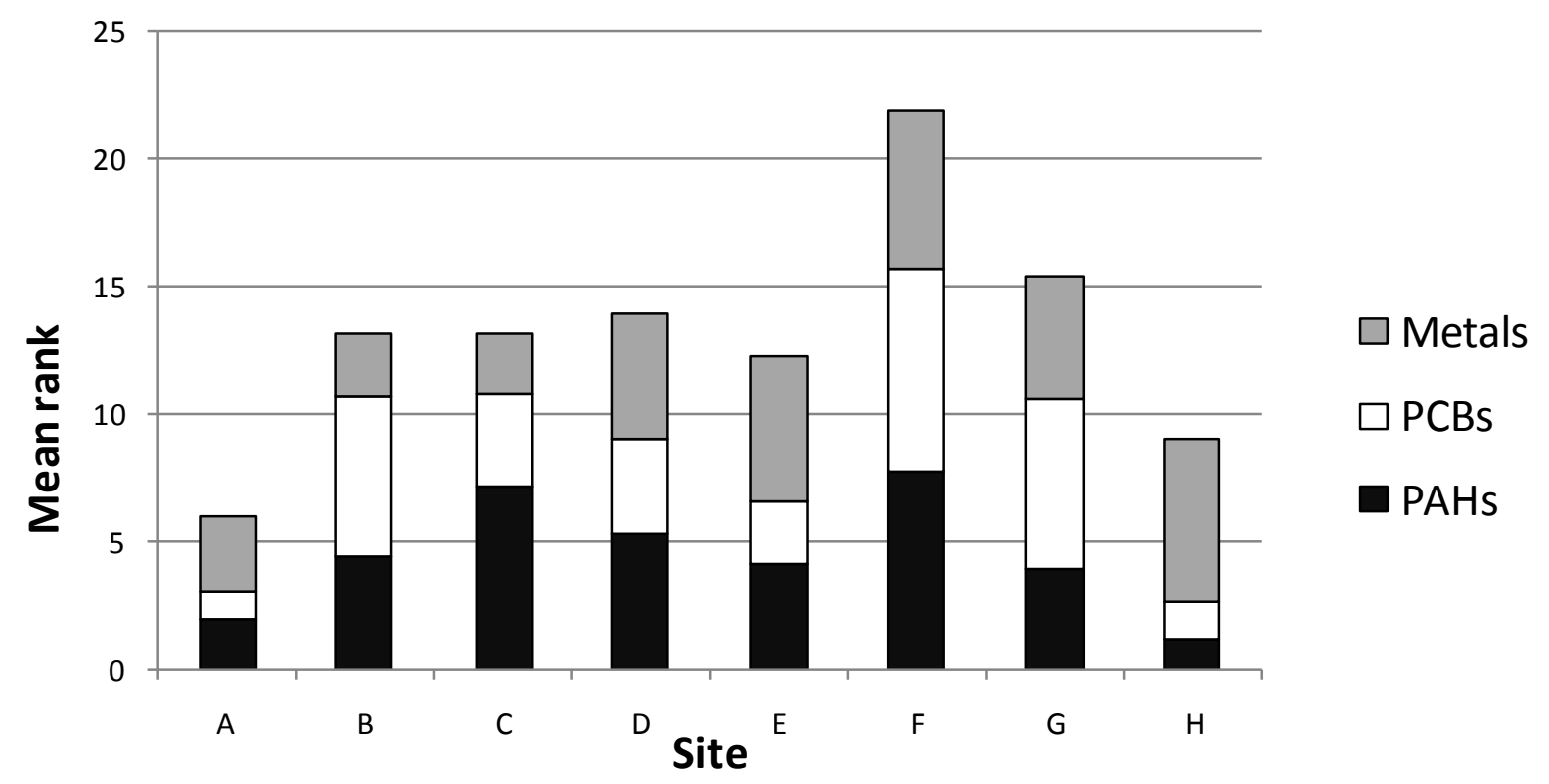


Figure 5 : Distribution of the computed IBR values for 2 sites, with an example of a non normal (site A) and a normal (site G) distribution.
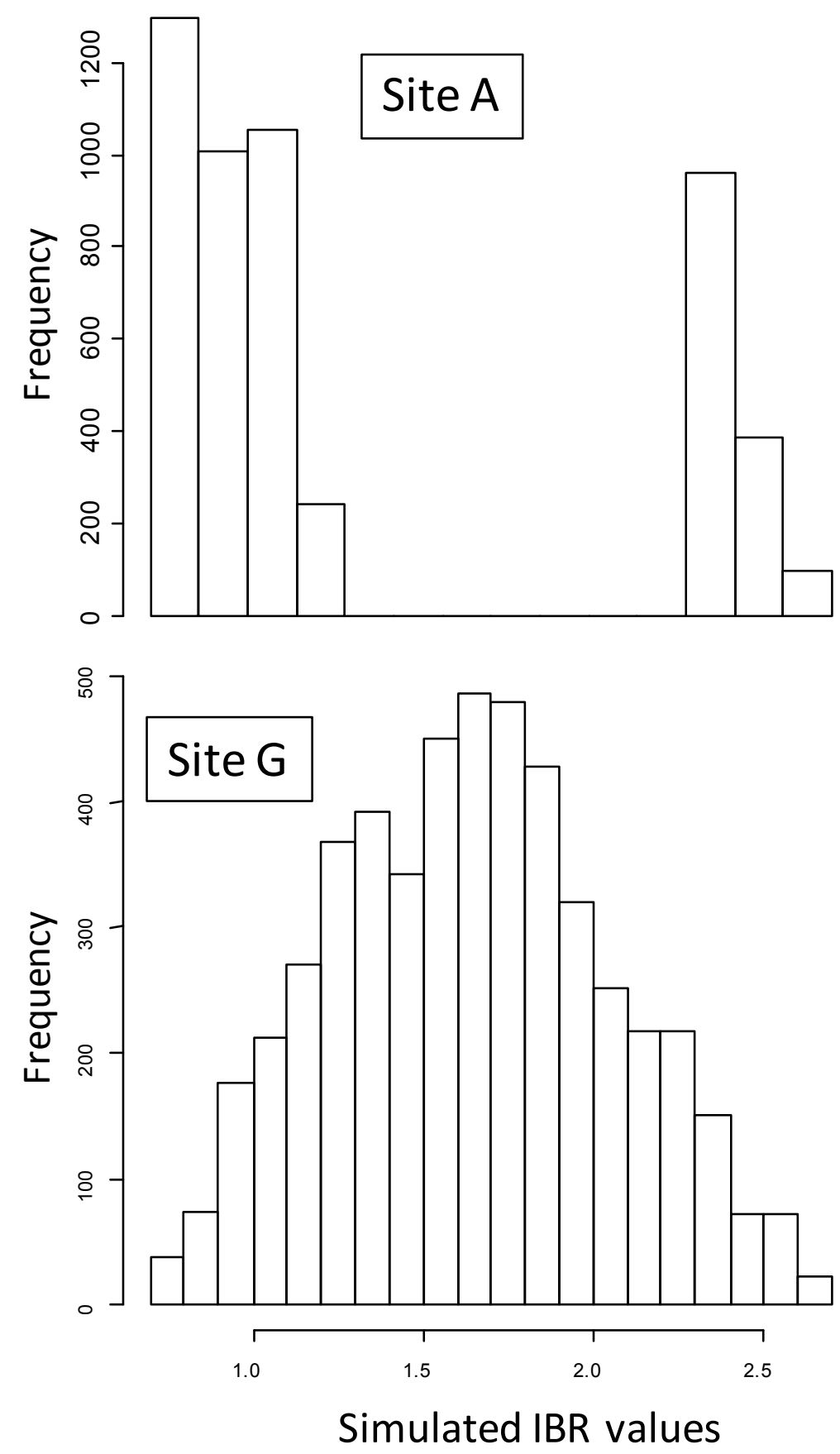
Figure 6: (a) Star plot for two permutations among the 5040 possibilities. The final area defined by the 8 triangles is modified according to the biomarker arrangement (b). (c) Site classification resulting from those two permutations - sites are arranged from the lowest to the highest IBR values

(a)

Biomarker responses : permutation 273

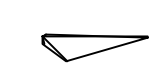

Site A

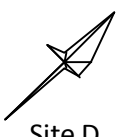

Site D

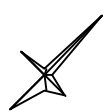

Site G

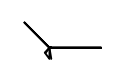

Site B

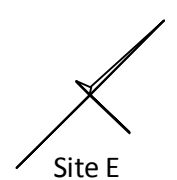

(b)

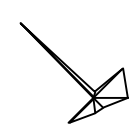

Site $\mathrm{H}$
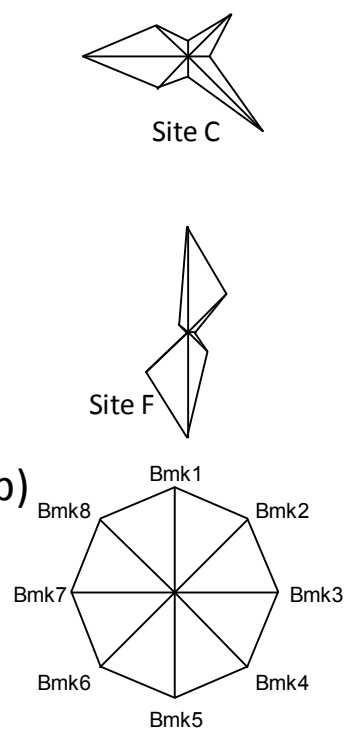

Biomarker responses : permutation 4928
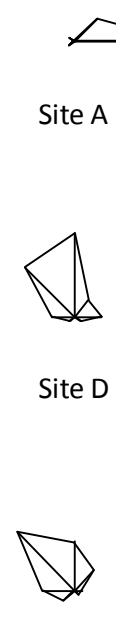

Site $G$
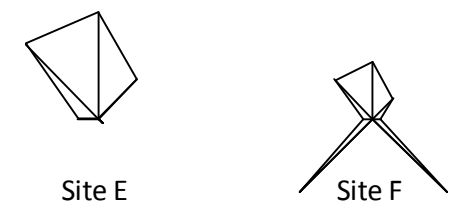

(b)
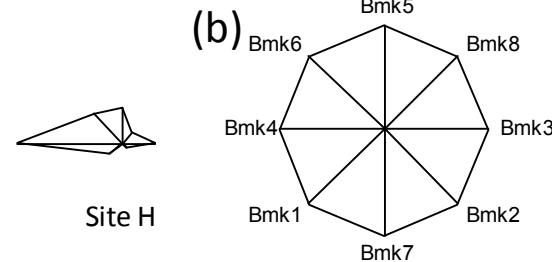

(c)

\begin{tabular}{ccc} 
& \multicolumn{2}{c}{ Rank } \\
\cline { 2 - 3 } Site & 273 & 4928 \\
\hline A & 6 & 2 \\
B & 1 & 1 \\
C & 8 & 7 \\
D & 5 & 6 \\
E & 2 & 8 \\
F & 7 & 3 \\
G & 3 & 4 \\
H & 4 & 5 \\
\hline
\end{tabular}


Table 1: Contaminant concentrations in the sediments for the 8 studied sites.

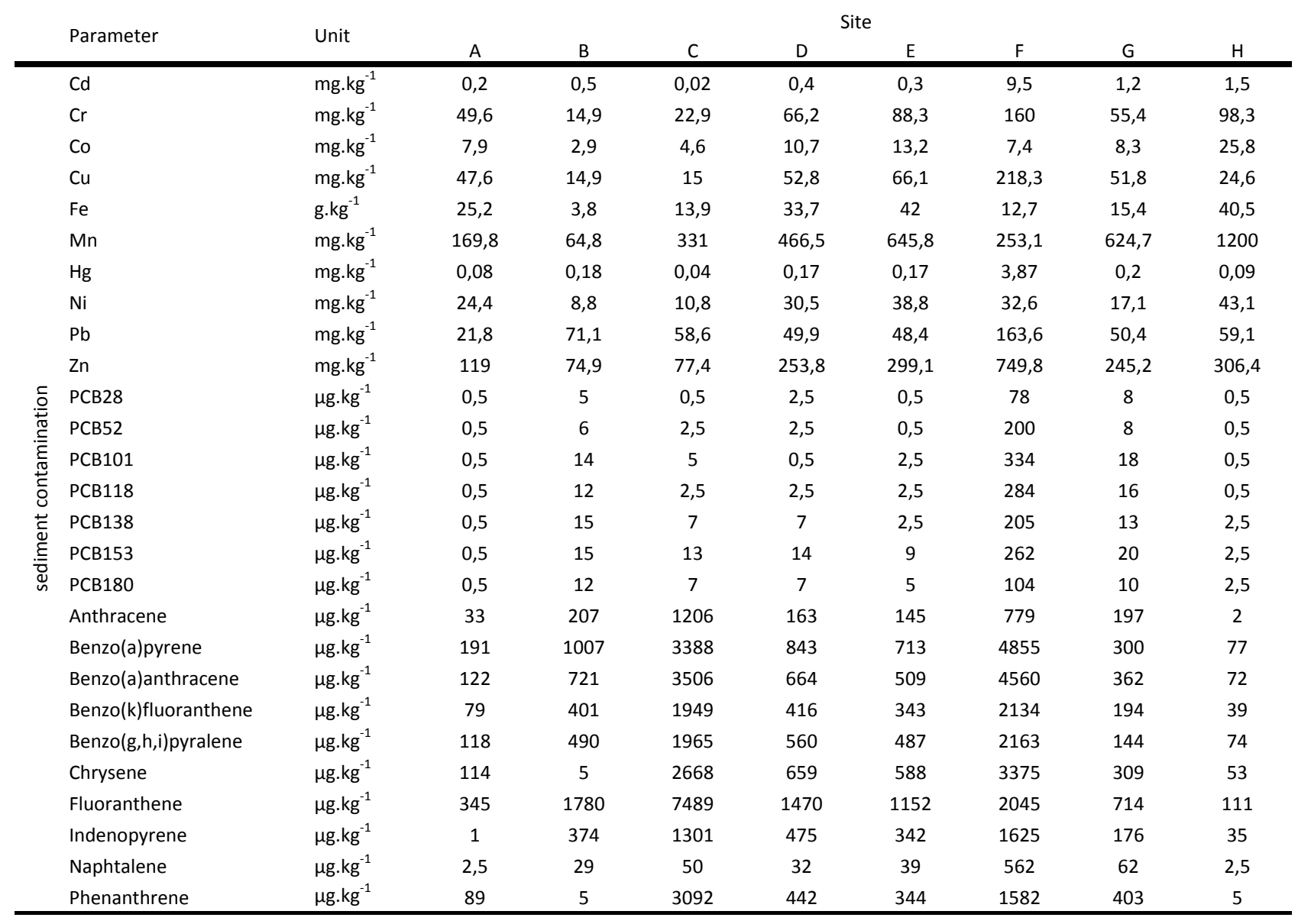

Table 2: Variation of the IBR values and ranks across the 5040 possible arrangements of the eight biomarkers considered.

\begin{tabular}{ccccccc} 
& \multicolumn{2}{c}{ Minimum } & \multicolumn{2}{c}{ Maximum } & \multicolumn{2}{c}{ Median } \\
& IBR value & Rank & IBR value & Rank & IBR value & Rank \\
\hline A & 0.0 & 1 & 1.3 & 6 & 0.2 & 1 \\
B & 0.0 & 1 & 0.8 & 4 & 0.2 & 2 \\
C & 4.3 & 6 & 8.1 & 8 & 6.0 & 8 \\
D & 0.8 & 2 & 3.1 & 6 & 1.7 & 4 \\
E & 0.2 & 1 & 5.6 & 8 & 2.5 & 6 \\
F & 1.9 & 3 & 7.3 & 8 & 4.4 & 7 \\
G & 0.7 & 2 & 2.6 & 6 & 1.6 & 3 \\
H & 0.9 & 2 & 3.2 & 7 & 2.1 & 5 \\
\hline
\end{tabular}

